\title{
ANALYSIS OF TRENDS IN TOTAL AND AIDS- RELATED DEATHS CERTIFIED AT MOSVOLD HOSPITAL, INGWAVUMA, KWAZULU-NATAL, FROM 2003 TO 2008
}

\author{
C H Vaughan Williams, $M B B S, D C H$, MFamMed, $D O H$ \\ District Family Physician, Umkhanyakude Health District Office, Jozini, KwaZulu-Natal
}

Objectives. To analyse mortality trends from deaths registered at Mosvold Hospital, Ingwavuma, KwaZulu-Natal, and possible impact of programmes to treat and prevent HIV infection.

Design. Longitudinal study of death certifications from 2003 to 2008.

Setting. Mosvold Hospital mortuary, Ingwavuma.

Subjects. Counterfoils of form 83/BI-1663, Notification/Register of Death/Stillbirths (Republic of South Africa, Department of Home Affairs), completed at Mosvold Hospital from January 2003 to December 2008.

Outcome measures. Age at death, cause of death, patterns of deaths grouped by age, gender and cause of death.

Results. AIDS-related deaths were the cause of $53 \%$ of deaths, particularly affecting the 20 - 59 -year and under- 5 age groups. Since 2005 there has been a decline in deaths in the 20 - 59 age group and an increase in average age at death.

Conclusions. The decrease in mortality from 2005 may be associated with antiretroviral roll-out reducing mortality from AIDS-related illnesses.

Mosvold Hospital is situated in northern KwaZuluNatal near the borders of Swaziland and Mozambique. According to estimates by the Department of Health, the hospital serves a population of about $108000 .{ }^{1}$ The population is rural and poor, with adult unemployment at $60 \%$. Five per cent of households have piped water and 3.6\% of households are supplied with electricity. Government health care in the Ingwavuma sub-district, in which Mosvold Hospital is situated, is provided by the hospital, 10 residential clinics and 3 mobile clinic teams. The hospital mortuary is the only government mortuary serving the Mosvold sub-district. Most deaths occurring in the sub-district, both within and outside the hospital, are certified by medical staff.

Antiretroviral drugs (ARVs) were first prescribed in September 2004 as part of the national antiretroviral rollout programme. Table I shows the total number of patients started on ARVs from 2004 to 2008. The number of females started in each year was greater than the number of males, and from the beginning of the roll-out at least $11 \%$ of the patients enrolled were children.
In a previous study, an analysis of 4 years' mortality data from 2003 to 2006 indicated that AIDS-related illnesses were responsible for $53 \%$ of deaths certified at the hospital during the period of the study. There was evidence of an increase in average age at death of women between 2005 and 2006, suggesting a positive impact of the ARV roll-out. The present analysis investigated the continuing impact of HIV/AIDS on mortality and life expectancy and observed trends over the period during which HIV treatment and prevention of mother-to-child transmission therapy (PMTCT) were introduced.

The use of nevirapine for PMTCT was commenced in 2002. Dual PMTCT, adding zidovudine to nevirapine, was started in April 2008.

\section{METHODS}

Data from counterfoils of form 83/BI-1663, Notification/ Register of Death/Stillbirths (Republic of South Africa, Department of Home Affairs), completed at Mosvold Hospital from 1 January 2003 to 31 December 2008, were entered into a database (Microsoft Access). 


\section{ETHICAL CONSIDERATIONS}

The publication of statistics on the causes of death certified at Mosvold Hospital was approved by the Mosvold Hospital Ethical Committee.

\section{RESULTS}

Figs 1 and 2 show age at death in males and females according to HIV-related and non-HIV-related causes.
Most deaths between the ages of 20 and 54 years are due to AIDS-related causes.

Table II shows the average age at death by year for males and females (>9 years) between 2003 and 2008 according to AIDS-related and non-AIDS-related causes. Average age at death for females declined between 2003 and 2005, and appeared to increase again from 2005 and 2007. The pattern for male deaths is less marked.

\begin{tabular}{|clllllll|}
\multicolumn{8}{c|}{ TABLE I. PATIENTS STARTED ON ANTIRETROVIRAL DRUGS AT MOSVOLD HOSPITAL, INGWAVUMA, } \\
KWAZULU-NATAL, FROM SEPTEMBER 2004
\end{tabular}

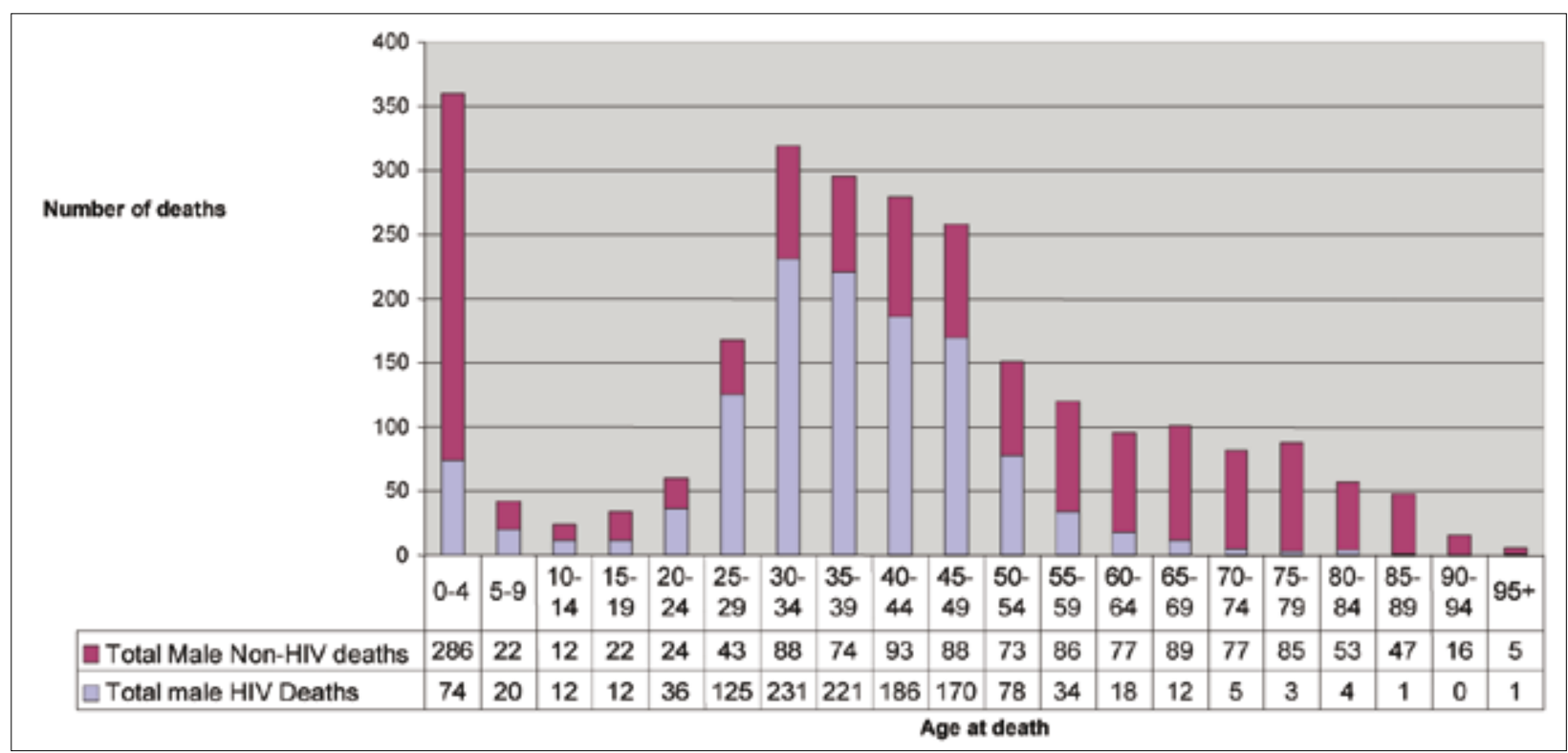

Fig. 1. Total male deaths 2003 - 2008 certified at Mosvold Hospital, Ingwavuma, northern KwaZulu-Natal, grouped according to HIV/AIDS-related and non-HIV/AIDS-related causes of death.

Number of deaths

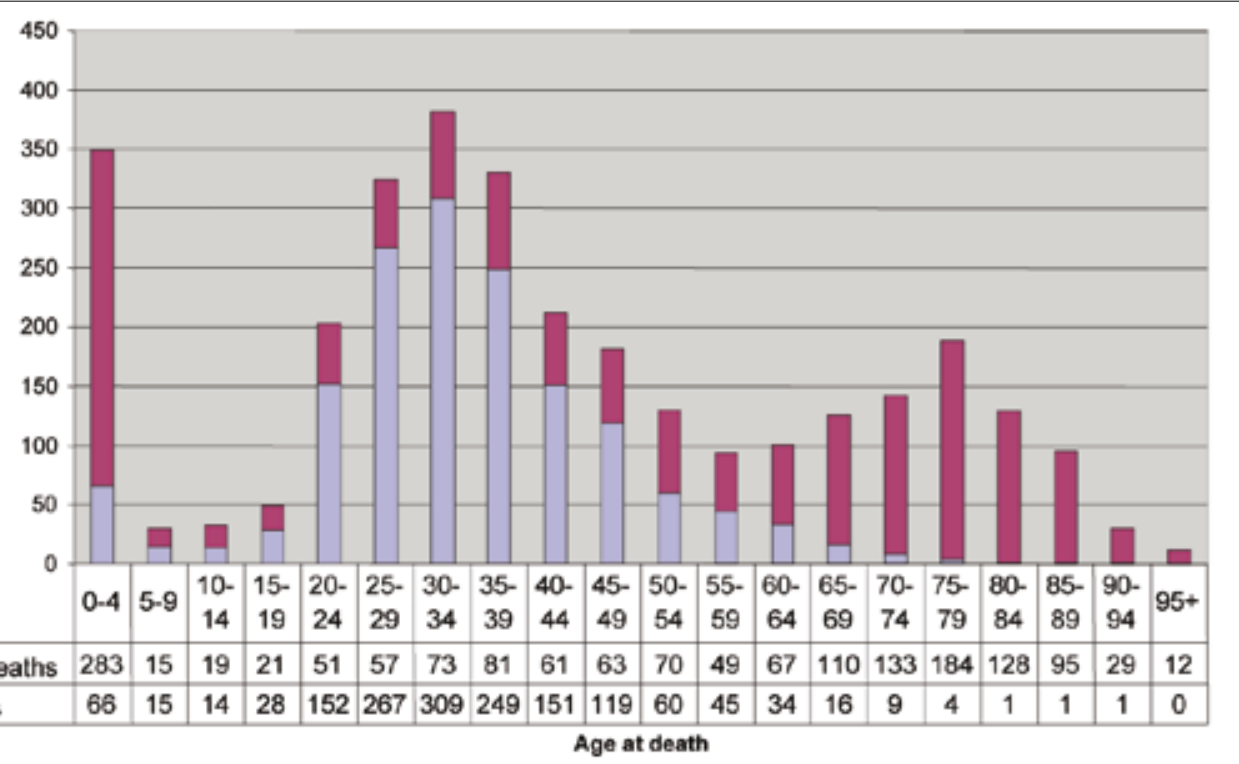

Fig. 2. Total female deaths 2003 - 2008 certified at Mosvold Hospital, Ingwavuma, northern KwaZulu-Natal, grouped according to HIV/AIDS-related and non-HIV/AIDS-related causes of death. 
Fig. 3 shows the trends in number of deaths certified at Mosvold Hospital for the 15 - 59-year age group and deaths attributable to AIDS-related causes. There is a 39\% reduction in all-cause mortality and a 38\% reduction in AIDS-related deaths in women and a 24\% reduction in all-cause mortality in men with a $29 \%$ reduction in deaths attributable to AIDS.

\section{DISCUSSION}

The National HIV and Syphilis Survey South Africa in $2007^{3}$ estimated the antenatal HIV prevalence for Umkhanyakude District to be $39.8 \%$, an increase on the 2006 estimate of $36.3 \%$ and higher than the national estimate of $28 \%$. High mortality from HIV/AIDS is consistent with these estimates.

In a survey of HIV infection prevalence in the southern part of Umkhanyakude District, near Mtubatuba, Tanser et al. ${ }^{4}$ found that HIV prevalence peaked at $51 \%$ in women in the 25 - 29-year age group and at $44 \%$ for men aged $30-34$ years, which is consistent with the mortality patterns found in this study of a population in the same district.

In a report by Statistics South Africa entitled 'Mortality and causes of death in South Africa, 2006, ${ }^{5}$ the proportion of deaths according to age group had a similar pattern to that found in this study, with peaks in the under-5, $30-34$ and, for females, 75 - 79-year age groups. Deaths in the $15-59$-year age group increased between 2002 and 2006, but with a decreasing annual increase between 2005 and 2006 compared with previous years.

The pattern of mortality according to age at death and cause of death in this study shows that HIV/AIDS is a leading cause of mortality in persons between the ages of 15 and 59, as well as causing substantial mortality in the under- 5 age group. However, the decline in deaths in the 15 - 59 age group after 2005, mostly AIDS related, combined with increased age at death since the

TABLE II. AVERAGE AGE OF DEATH IN PERSONS AGED > 9 YEARS - DEATHS CERTIFIED AT MOSVOLD HOSPITAL, INGWAVUMA, KWAZULU-NATAL, JANUARY 2003 - DECEMBER 2008

\begin{tabular}{|c|c|c|c|c|c|}
\hline \multirow[b]{2}{*}{ Year } & & \multicolumn{2}{|l|}{ Males } & \multicolumn{2}{|l|}{ Females } \\
\hline & & Average age at death & $95 \% \mathrm{Cl}$ & Average age at death & $95 \% \mathrm{Cl}$ \\
\hline \multirow[t]{2}{*}{2003} & All causes & 47.5 & $45.8-49.2$ & 48.5 & $46.6-50.4$ \\
\hline & HIV/AIDS & 39.4 & $38.0-40.8$ & 35.1 & $33.7-36.5$ \\
\hline \multirow[t]{2}{*}{2004} & All causes & 45.6 & $43.9-47.3$ & 45.3 & $43.5-47.1$ \\
\hline & HIV/AIDS & 38.8 & $37.5-40.1$ & 36.2 & $34.9-37.5$ \\
\hline \multirow[t]{2}{*}{2005} & All causes & 45.9 & $44.2-47.6$ & 44.1 & $42.4-45.7$ \\
\hline & HIV/AIDS & 37.9 & $36.5-39.3$ & 35.9 & $34.6-37.2$ \\
\hline \multirow[t]{2}{*}{2006} & All causes & 45.6 & $43.8-47.3$ & 47.7 & $45.8-49.6$ \\
\hline & HIV/AIDS & 38.7 & $37.2-40.2$ & 35.4 & $33.9-36.8$ \\
\hline \multirow[t]{2}{*}{2007} & All causes & 47.54 & $45.7-49.4$ & 50.01 & $48.0-52.0$ \\
\hline & HIV/AIDS & 39.62 & $38.1-41.2$ & 37.17 & $35.5-38.8$ \\
\hline \multirow[t]{2}{*}{2008} & All causes & 47.31 & $45.3-49.3$ & 49.06 & $46.8-51.3$ \\
\hline & HIV/AIDS & 40.62 & $38.7-42.6$ & 35.1 & $33.4-36.8$ \\
\hline $\mathrm{Cl}=\mathrm{C}$ & ival. & & & & \\
\hline
\end{tabular}

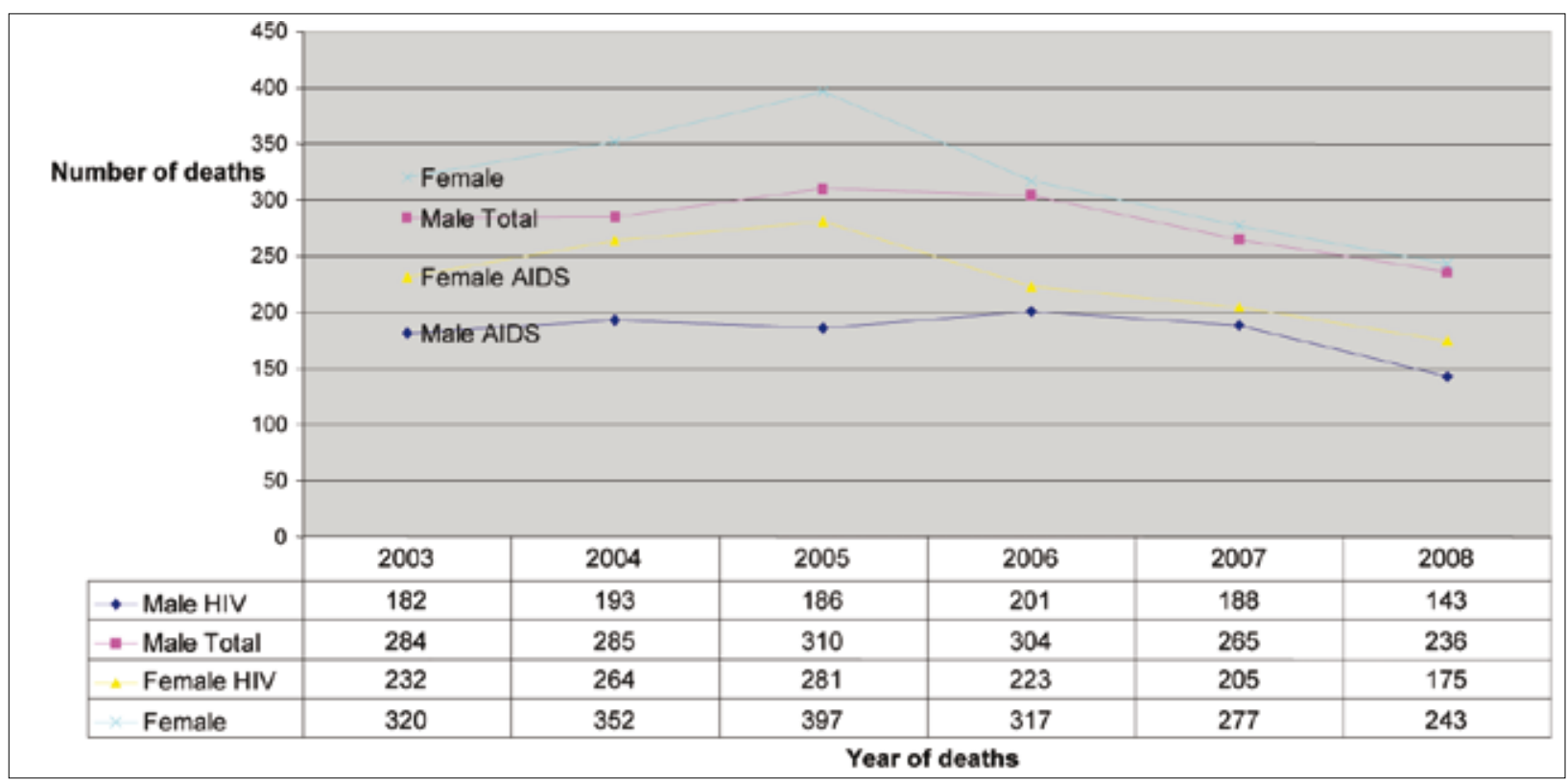

Fig. 3. Deaths per year in the age group 15 - 59 years certified at Mosvold Hospital, Ingwavuma, KwaZulu-Natal. 
start of the ARV roll-out, suggests that roll-out may be reducing mortality from AIDS-related illness in the 15 59-year age group. The greater impact on female mortality compared with male mortality may be explained by the greater number of females compared with males enrolled onto ARV treatment.

\section{REFERENCES}

1. Zondi $\mathrm{T}$, Ngomane N. Health and health care systems situational analysis. In: Umkhanyakude Health District Situational Analysis. Braamfontein: Health Systems Trust, 2002: 10.
2. Vaughan Williams $\mathrm{CH}$. Analysis of impact of HIV/AIDS on deaths certified at Mosvold Hospital, Ingwavuma, northern KwaZulu-Natal from 2003 - 2006. South African Journal of Family Practice 2007; 49(5): 16a-16e. http://www.safpj.co.za/ index.php/safpj/article/view/628/756 (accessed 15 June 2009).

3. National Department of Health, South Africa. 2008. The National HIV and Syphilis Survey South Africa 2007. http://www.doh.gov.za/docs/reports/2007/antenatal/ antenatal_report.pdf (accessed 14 June 2009).

4. Tanser $F_{1}$ Hosegood $V$, Bärnighausen $T$, et al. Cohort profile: Africa Centre Demographic Information System (ACDIS) and population-based HIV survey. Int J Epidemiol 2008; 37: 956-962. http://www.pubmedcentral.nih.gov/articlerender. fcgi?artid=2557060 (accessed 15 June 2009).

5. Statistics South Africa. 2008. Statistical Release P0309.3: Mortality and causes of death in South Africa, 2006 Findings from death notification. http://www.statssa. gov.za/publications/statsdownload.asp?PPN=P0309.3\&SCH=4254 (accessed 14 June 2009). 